\title{
Frontotemporal dementia and mitochondrial DNA transitions
}

\author{
Manuela Grazina, ${ }^{\text {a,b }}$ Filipe Silva, ${ }^{\text {b,c }}$ Isabel Santana, ${ }^{c}$ Beatriz Santiago, ${ }^{\mathrm{c}}$ Cândida Mendes, \\ Marta Simões, ${ }^{\mathrm{b}}$ Miguel Oliveira, ${ }^{\mathrm{b}}$ Luís Cunha, ${ }^{\mathrm{c}}$ and Catarina Oliveira ${ }^{\mathrm{a}, \mathrm{b}, \mathrm{c}, *}$ \\ ${ }^{a}$ Biochemistry Institute, Faculty of Medicine, University of Coimbra, 3004-504, Coimbra, Portugal \\ ${ }^{\mathrm{b}}$ Neurochemistry Department, Center for Neurosciences of Coimbra, University of Coimbra, 3004-517, Coimbra, Portugal \\ ${ }^{\mathrm{c}}$ Neurology Unit, University Hospital of Coimbra, 3000-075, Coimbra, Portugal
}

Received 16 May 2003; revised 3 November 2003; accepted 5 November 2003

\begin{abstract}
Frontotemporal dementia (FTD) is the second most common type of primary degenerative dementia. Some patients present an overlap between Alzheimer's disease (AD) and FTD both in neuropathological and clinical aspects. This may suggest a similar overlap in physiopathology, namely an involvement of mitochondrial DNA (mtDNA) in FTD, as it has been associated to AD. To determine if mtDNA is involved in FTD, we performed a Polymerase Chain ReactionRestriction Fragment Length Polymorphism (PCR-RFLP) analysis, specific to mtDNA $N A D H$ Dehydrogenase subunit 1 (ND1) nucleotides 3337-3340, searching for mutations previously described in Parkinson's and AD patients. We could identify one FTD patient with two mtDNA transitions: one already known (3316 G-to-A) and another unreported (3337 G-to-A). Additionally, mitochondrial respiratory chain complex I activity was reduced in leukocytes of this patient $(36 \%$ of the control mean activity). To our knowledge, this is the first report of mtDNA variants in FTD patients.

(C) 2004 Elsevier Inc. All rights reserved.
\end{abstract}

Keywords: Frontotemporal dementia; mtDNA; ND1; 3316; 3337; Point mutation; Mitochondrial respiratory chain; Hominoid primates; Age of onset; $A P O E$ gene

\section{Introduction}

Frontotemporal dementia (FTD) is the second most common type of primary degenerative dementia (Andreasen et al., 1999; Brun, 1993). FTD is the generic designation of a group of disorders, which includes Frontal Lobe Dementia, Pick Disease and Motor Neuron Disease (Brun et al., 1994), as well as inherited neurodegenerative diseases that have been linked to chromosome 17, termed FTDP-17 (Lee et al., 2001). Although these dementias have been difficult to characterise due to their clinical variability, the most common feature is a predominant frontal lobe syndrome (Sjögren et al., 1997), which sometimes can also be observed in more severe cases of Alzheimer's disease (AD) and in Vascular

* Corresponding author. Biochemistry Institute, Faculty of Medicine, University of Coimbra, Rua Larga, 3004-504, Coimbra, Portugal. Fax: +351-239-822776.

E-mail address: catarina@cnc.cj.uc.pt (C. Oliveira).

Available online on ScienceDirect (www.sciencedirect.com.)
Dementia (Neary, 1990). The early appearances of behavioural symptoms, mild memory impairment and preservation of spatial orientation are the most remarkable differences between FTD and AD (Barber et al., 1995). Parkinsonian symptoms and motor neuron dysfunction may be observed in special forms of FTD and are useful in the differentiation between the two conditions (Foster et al., 1997). Because it often affects people or families in midlife, FTD is also frequently confused with primary psychiatric disorders (McKhann et al., 2001; Stevens et al., 1998).

Neuropathology in FTD is characterised by loss of neurons, neuropil vacuolation and gliosis in the superficial cortical layers of the frontal and anterior temporal lobes (Brun, 1993), basal ganglia and substantia nigra (Rizzu et al., 1999), and by the presence of pathological tau proteins (Vermersch et al., 1995), which are also observed in the brain of AD patients (Foster et al., 1997; Sjögren et al., 2000; Spillantini et al., 1998). Tau protein is a phosphoprotein associated with microtubules and responsible for its assembly and stabilization (Goedert et al., 1991). Self-association of hyperphosphorylated and insoluble form of tau protein in straight and twisted filaments creates argyrophilic or T-positive neuropil inclusions with or without the characteristics of pick bodies or ballooned neurons, as well as argyrophilic or T-positive glial inclusions (Spillantini et al., 1998). The biochemical analyses of tau protein abnormalities have proven to be useful in the classification of FTD (Dickson, 1997).

By linkage analysis, FTDP-17 was localized at chromosome 17q21-q23 (Lynch et al., 1994) and Wilhelmsen et al. (1994) mapped the disinhibition-dementia-parkinsonism-amyotrophy complex locus to $17 \mathrm{q} 21-\mathrm{q} 22$. The first missense and splice site mutations in a family pedigree with FTDP-17 were found in the tau gene (Hutton et al., 1998), and several mutations have been described ever since in this gene among the different families with cases diagnosed as FTDP-17 (Buée and Delacourte, 2001). However, only $10-15 \%$ of cases of FTD exhibit mutations in the Tau gene (Wilhelmsen et al., 2001). Raux et al. (2000) found a previously unreported heterozygous CTA-to-CCA mutation at codon 113 of the Presenilin 1 (PS1) gene, and this finding implies that the presence of $P S 1$ mutations must be considered in FTD pedigrees with no detectable Tau gene mutation. Recently, Gydesen et al. (2002) have identified and studied a large kindred with FTD inherited as an autosomal dominant trait, which was mapped to the pericentromeric region of chromosome 3, suggesting that 
there is another gene involved in the etiology of some forms of FTD. Also, a Swiss FTD kindred showed several recombination events for chromosomes 3 and 17, but patients shared a haplotype on chromosome $9 \mathrm{q} 21-22$, indicating that Tau is not at the origin of FTD in this family (Savioz et al., 2003).

Chang et al. (1995) reported a patient with FTD and motor neuron disease with neuronal ultrastructural abnormalities and hypothesized that a mitochondrial dysfunction or defective transport of mitochondria into axonal processes could be a potential cause for the co-association.

Due to the neuropathological and clinical overlapping of $\mathrm{AD}$ and FTD, mitochondrial DNA (mtDNA) may be a causal factor for both diseases. According to several reports, we have recently reported mtDNA mutations in two AD patients (unpublished results). To analyse the possibility of the mtDNA NADH Dehydrogenase subunit 1 (ND1) gene being involved in FTD, we have studied 3 FTD patients and 21 healthy age-matched control subjects mtDNA ND1 gene nucleotides 3337-3340 using Polymerase Chain Reaction-Restriction Fragment Length Polymorphism (PCR-RFLP) analysis.

\section{Materials and methods}

We have studied three patients, one female (patient 1) and two male (patients 2 and 3), with diagnosis of FTD (age range: 54-67 years, mean: $58.33 \pm 7.51$ years), as defined by standard criteria (Brun et al., 1994; McKhann et al., 2001), followed at the Neurological Unit of the University Hospital of Coimbra. Global cognitive impairment was quantified using the Mini-Mental State Examination (MMSE) (Folstein et al., 1975) and global dementia severity was staged as mild, moderate and severe. Twenty-one healthy age-matched control subjects free of progressive neurological disorders, 14 female and 7 male (age range: 54-67 years; mean: $60.19 \pm 4.57$ years), were randomly recruited at the Neurological Unit of the University Hospital of Coimbra, sharing similar socioeconomic status as the FTD patients. All the individuals mentioned in this study gave informed consent for the analyses performed.

We have extracted total cellular DNA (nuclear plus mitochondrial) from peripheral leukocytes, isolated from blood after erythrocytes lysis, using a standard phenol-chloroform method. Polymerase Chain Reaction (PCR) was performed in a TGradient thermocycler (Biometra) to obtain a 289-base pair (bp) fragment. The amplification conditions were 30 cycles at $95^{\circ} \mathrm{C}$ for $30 \mathrm{~s}$, $57^{\circ} \mathrm{C}$ for $30 \mathrm{~s}$ and $72^{\circ} \mathrm{C}$ for $30 \mathrm{~s}$, using a master mix containing $0.25-0.5 \mu \mathrm{g}$ of total cellular DNA, $200 \mu \mathrm{M}$ each dNTP (Amersham Biosciences), 1 unit of Taq Polymerase (Amersham Biosciences), $1 \times$ Taq Polymerase Buffer (Amersham Biosciences) and $1 \mu \mathrm{M}$ of each primer PR5 (5'AAAGGACAAGAGAAATAAGGCC-3') and PR3 (5'-GGGCCTTTGCGTAGTTGTCT-3', specially designed with one mismatch for mutation specific (MS)-PCR for detection of wild-type mtDNA sequence at nucleotide 3397) in a final reaction volume of $25 \mu \mathrm{l}$. This procedure was followed by Restriction Fragment Length Polymorphism (RFLP) analysis with endonuclease Csp 6I (MBI-Fermentas), according to the manufacturer's instructions, which produces two fragments (79 and $210 \mathrm{bp}$ ) if the sequence is wild-type and only one if there is a mutation at any of the nucleotides 33373340. All the DNA samples were analysed randomly in a blinding way. Additionally, we used the same conditions to amplify $250 \mathrm{ng}$ of a DNA sample extracted from $\rho^{0}$ cells which are devoided of mtDNA (Parfait et al., 1998). Finally, to confirm the presence of a mutation, we have performed sequence analysis of purified fragments with GFX ${ }^{\mathrm{TM}}$ PCR DNA and Gel Band Purification Kit (Amersham Biosciences) using CEQ $^{\mathrm{TM}}$ DTCS-Quick Start Kit (Beckman Coulter) according to the manufacturer's instructions, and the reactions were analysed by $\mathrm{CEQ}^{\mathrm{TM}}$ 2000XL DNA Analysis System (Beckman Coulter) and compared to the Cambridge-Sequence of the human mitochondrial genome (Anderson et al., 1981).

Peripheral leukocytes were isolated from patient 1 and five healthy control subjects using $50 \mathrm{ml}$ of blood (in EDTA). The activities of the respiratory chain complexes I (NADH-cytochrome $c$ oxidoreductase; EC 1.6.5.3), II (succinate dehydrogenase; EC 1.3.5.1), II + III (succinate-cytochrome $c$ oxidoreductase; EC 1.10.2.2), IV (cytochrome $c$ oxidase; EC1.9.3.1), V (ATP synthase; EC 3.6.1.34) and citrate synthase (CS; EC 4.1.3.7) were evaluated as described (Rustin et al., 1994). The results of the enzymatic activities were expressed normalized to CS.

\section{Results}

We have found one FTD patient (patient 1) with a homoplasmic mtDNA mutation at nucleotides $3337-3340$ by PCR-RFLP analysis (Fig. 1). The affected subject was a 54-year-old woman and the diagnosis of disease occurred at the age of 52 years. Her mother had died at 63 years age with dementia. She presented early personality change, with unconcern and inappropriate behaviour, reduction in speech output and no spatial disorientation. The investigation confirmed the probable diagnosis of FTD. The electroencephalogram was normal; the computed tomography scan showed frontal atrophy and the characteristic pattern of frontotemporal hypoperfusion on single-photon emission computed tomography was observed. Two years later she presented stereotyped behaviour, speech was severely reduced and with echolalia and the

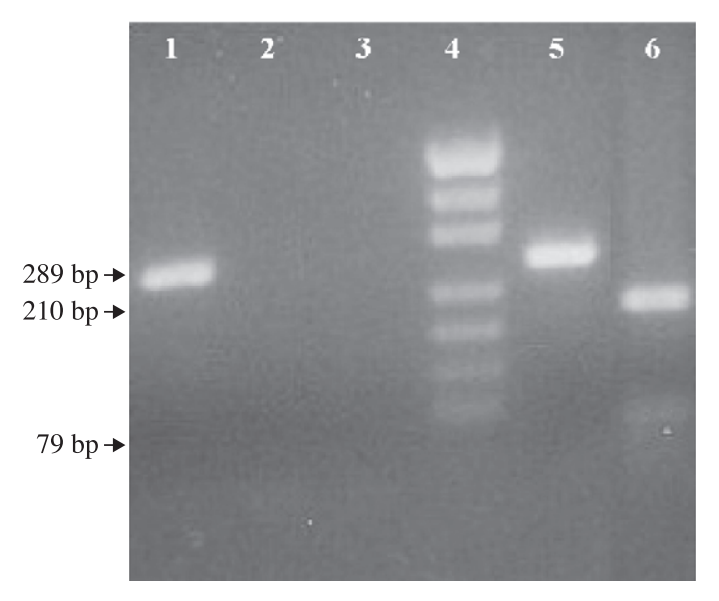

Fig. 1. Photograph under ultraviolet light of agarose gel stained with ethidium bromide showing mitochondrial DNA (mtDNA) fragments from restriction enzyme analysis of the PCR product of primers PR5 and PR3 using Csp 6I. (Lane 1) PCR product not digested; (Lane 2) PCR negative control; (Lane 3) $\rho^{0}$ cell DNA sample; (Lane 4) pUC19 DNA/Msp I (Hpa II) Marker 23, ready-to-use (MBI Fermentas); (Lane 5) FTD patient DNA sample; (Lane 6) healthy age-matched control DNA sample. 


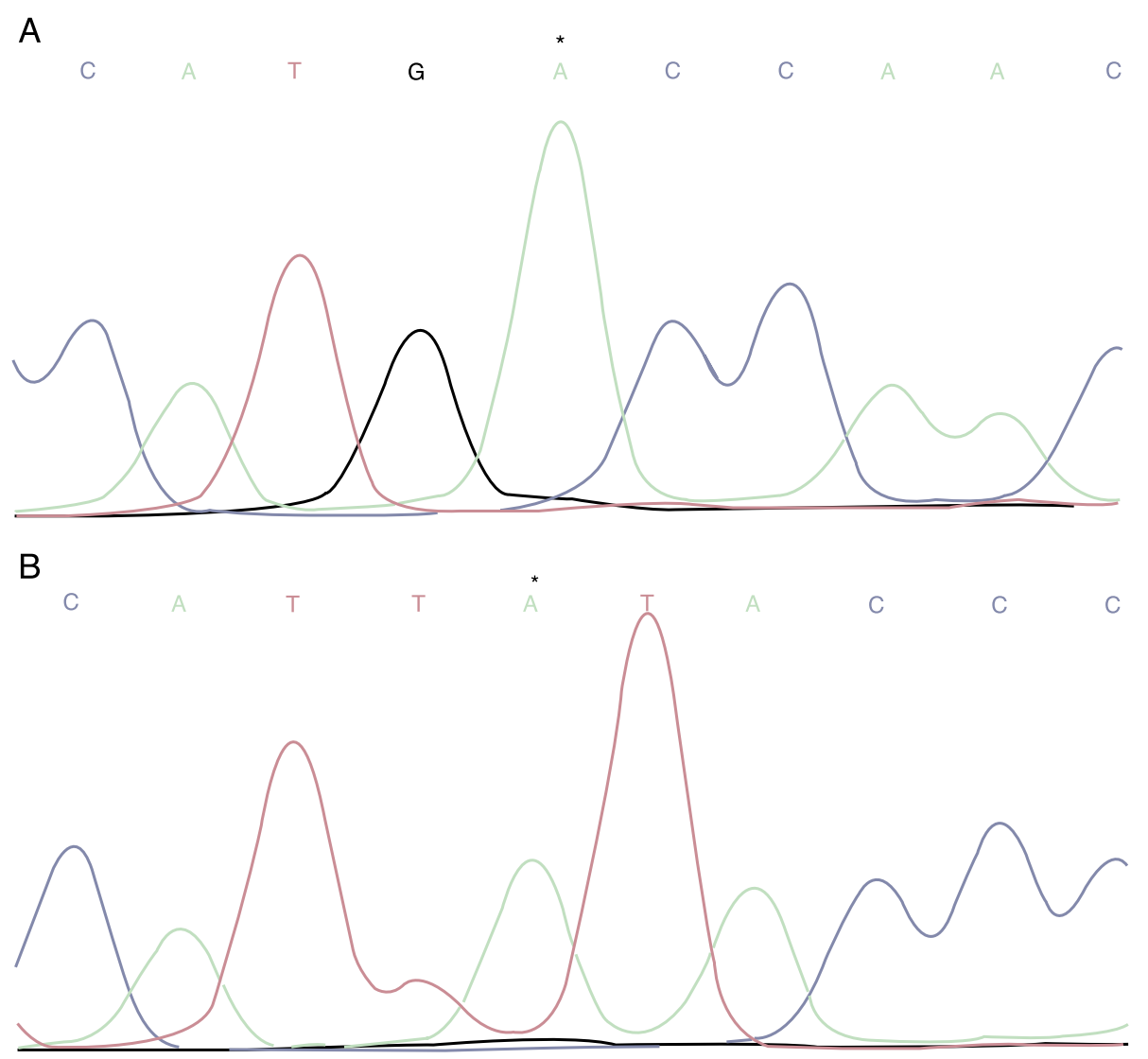

Fig. 2. Results of fluorescence-based automated sequencing analysis. (A) mtDNA sequence surrounding the nucleotide 3316A, marked with *. (B) mtDNA sequence surrounding the nucleotide $3337 \mathrm{~A}$, marked with *.

cognitive or global assessment was compatible with severe dementia (MMSE 8).

The PCR-RFLP result was confirmed by sequence analysis. This patient presented an unreported transition G-to-A at nucleotide 3337 of the mtDNA ND1 gene, which promotes the change of valine to methionine in the peptide chain (Fig. 2). Additionally, this patient presented a known G-to-A transition at nucleotide 3316 of the mtDNA ND1 gene (Fig. 2), which promotes the change of alanine to threonine in the peptide chain. This transition was first described in non-insulin-dependent diabetes mellitus (NIDDM) patients (Nakagawa et al., 1995) and was also described in patients with adult and childhood insulin-dependent diabetes mellitus, NIDDM and impaired glucose tolerance (Fukuda et al., 1999; Ji et al., 2001; Matsuura et al., 1999; Nakano et al., 1998; Odawara et al., 1996). This substitution was also reported in patients with mitochondrial disorders (Matsumoto et al., 1999;

Table 1

Mitochondrial respiratory chain enzymatic activities in leukocytes

\begin{tabular}{lcllll}
\hline & I/CS & II/CS & II + III/CS & IV/CS & V/CS \\
\hline Patient 1 & $0.0025^{\mathrm{a}}$ & 0.16 & 0.31 & 1.27 & 0.41 \\
Controls $(n=5)$ & & & & \\
Mean & 0.0070 & 0.21 & 0.32 & 1.15 & 0.55 \\
SD & 0.0027 & 0.07 & 0.10 & 0.31 & 0.22 \\
Minimum & 0.0042 & 0.14 & 0.19 & 0.81 & 0.36 \\
Maximum & 0.0102 & 0.30 & 0.45 & 1.43 & 0.81 \\
\hline
\end{tabular}

${ }^{a}$ This value is $36 \%$ of the control mean activity.
Sternberg et al., 1998) and dilated cardiomyopathy (Arbustini et al., 1998).

Another important fact is that no amplification of the $\rho^{0}$ cell DNA sample could be observed (Fig. 1). The three FTD patients presented a $\varepsilon 3 / \varepsilon 3$ genotype at $A P O E$ gene, studied according to Crook et al. (1994).

The analysis of the mitochondrial respiratory chain enzymatic activities revealed a deficiency of complex I (36\% of the control mean activity) in leukocytes of the patient carrying the mtDNA transitions described (patient 1). Results are summarized in Table 1.

\section{Discussion}

In a group of FTD patients and healthy age-matched control subjects, we have identified two homoplasmic mtDNA variants in one patient. The patient presented changes in nucleotides 3316 and 3337 of the mtDNA ND1 gene. The first alteration $(3316 \mathrm{G}$ to-A) promotes the change of a nonpolar alanine to a polar threonine in an essentially hydrophobic peptide, a nucleotide substitution that has been described in diabetes mellitus patients (Fukuda et al., 1999; Matsuura et al., 1999; Nakano et al., 1998; Odawara et al., 1996). However, the FTD patient in study does not present any clinical evidence of diabetes mellitus. Evolutive studies consider this alteration as weakly conserved among hominoid primates (Anderson et al., 1981; Horai et al., 1995) (Fig. 3) and was reported as a polymorphism related with haplogroup A, present in the Asian populations (Herrnstadt et 
A

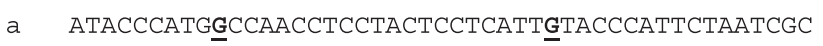

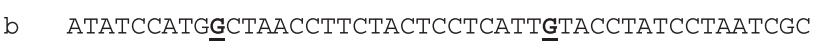

C ACACCCATGA-ACAACCTCCTACTCCTCATTGTACCCATCCTAATCGC

d ACACCCATGACTAACCTCCTACTCCTCATTGTACCTGTCCTAATCGC

e ATGCCTGTA

B

a MPMANLLLLIVIPILIAMAFLMLTERKILGYMQLRKGPNVVGPYG

b MSMANLLLLIVEPILIAMAFLMLTERKILGYMQLRKGPNVVGPYG

C TPMTNLLLLIVPILIAMAFLMLTERKILGYMQLRKGPNIVGPYG

d TPMTNLLLLIVPPVIAMAFLMLTERKILGYMQLRKGPNIVGPYG

e MPVINLLLLTMSILIAMAFLMLTERKILGYTQLRKGPNIVGPCG

Fig. 3. Evolutionary conservation among hominoid primates (Homo sapiens (a), G. gorilla (b), Pan troglodytes (c), Pan paniscus (d) and P. pygmaeus (e)). (A) 5'mtDNA sequence of NADH Dehydrogenase subunit 1 gene surrounding nucleotides 3316 and 3337 underline and bold. (B) Nterminal amino acid sequence of NADH Dehydrogenase subunit 1 protein with amino acid coded by nucleotides 3316 and 3337 underline and bold. $H$. sapiens mtDNA sequence obtained from Anderson et al. (1981). G. gorilla, $P$. troglodytes, $P$. paniscus and $P$. pygmaeus mtDNA sequences were obtained from Horai et al. (1995).

al., 2002). The second alteration (3337 G-to-A) promotes the change of a valine to a methionine in the ND1 peptide, a nucleotide substitution that is reported here for the first time, to our knowledge. However, the absence of Rsa I cleavage site was described before in several samples at nucleotide 3337 (Macaulay et al., 1999). This may be due to a change at nucleotide 3337 but, as Rsa I recognizes the same nucleotide sequence as Csp 6I, the absence of cleavage may be due to a change in any of the four nucleotides 3337, 3338, 3339 and 3340, because no sequencing analysis was performed to confirm the PCR-RFLP results. The nucleotide 3337 is quite conserved among hominoid primates. However, in Pongo pygmaeus (orangutan), there is an A instead of a $G$ in the DNA sequence, corresponding to a methionine instead of a valine in the ND1 peptide (Fig. 3). To our knowledge, this is the first report of mitochondrial DNA variants in frontotemporal dementia patients.

It is quite remarkable that this patient presents two alterations in the same region of the mtDNA ND1 gene, suggesting a possible involvement of mitochondrial ND1 in the etiopathogenesis of FTD. Such substitutions may have a functional meaning causing the reduction of respiratory chain complex I activity and contributing to the pathogenesis of the disorder. In fact, we could confirm a reduction of $64 \%$ (compared to the control mean) of the complex I activity in leukocytes of patient 1 , reinforcing the possible involvement of the mitochondrial respiratory chain in FTD. Moreover, it is necessary to consider that those changes may be associated with other mitochondrial or nuclear mutations and polymorphisms, influencing the severity of FTD or even the onset of the disease. The mtDNA mutations may have a cumulative effect, increasing the probability to develop an energy failure. Recently, we have reported three mtDNA variants in two AD patients: one patient was 68 years old ( 65 years of age at onset of disease) with a change at position 3199 of the $16 S$ rRNA mtDNA gene and the other was 54 years old (53 years of age at onset of disease) with two changes at positions 3197 of the $16 S$ rRNA mtDNA gene and 3338 of the mtDNA ND1 gene (unpublished results). Taking this into account and according to the results presented in this report, we may hypothesize that mutations in the mtDNA region 3197-3338 may decrease the age of onset of neurodegenerative disorders, probably due to an impairment of the mitochondrial respiratory chain or translation mechanisms. We are aware that additional studies are needed to confirm or refuse this hypothesis.

It is also necessary to be cautious in dealing with mtDNA due to its high mutation rate. In fact, mtDNA is a very susceptible molecule, taking into account inefficient repair systems, absence of protective histones, rare noncoding regions and its localization near the electron transport chain. This is the main site of free radical production, which may contribute to mtDNA oxidative damage and additional injury, possibly involved in neurodegenerative cascades, whenever a certain threshold is reached.

The fact that there was no amplification of the $\rho^{0}$ cell DNA sample indicates that no nuclear pseudogenes were amplified and that we are studying the mtDNA genes of FTD patients and healthy age-matched control subjects.

Interestingly, the three FTD patients presented a $\varepsilon 3 / \varepsilon 3$ genotype for the $A P O E$ gene. Although we cannot exclude that it may be a coincidence favoured by the small number of samples studied, we can hypothesize that a higher probability of developing FTD may exist if $\varepsilon 4$ allele is absent of APO E genotype and a higher probability of developing $\mathrm{AD}$ exists when $\varepsilon 4$ allele is present. Certainly, further analysis may help to clarify this hypothesis.

Our results suggest that mutations in mtDNA ND1 nucleotides 3337-3340 do not account for a primary risk for developing FTD. However, it is not excluded that other sequence regions of $N D 1$ or other mtDNA genes can be involved in the pathogenesis or onset of FTD. In fact, our results indicate that mtDNA alterations in $16 \mathrm{~S}$ $r R N A$ gene and ND1 gene may account for some risk in neurodegenerative disorders.

\section{Acknowledgments}

The authors are grateful to Prof. A. Münich, Dr. P. Rustin and Dr. A. Rötig for providing $\rho^{0}$ cell DNA and to Histocompatibility Centre of Coimbra for providing the facilities for sequencing analysis. This work was partially supported by a scholarship from the Fundação para a Ciência e Tecnologia-Fundo Social Europeu, III Quadro Comunitário de apoio (PRAXIS XXI/BD/4049/94) and by a scholarship (prized project on Brain Aging, Alzheimer Disease and other Dementia) from the Sociedade Portuguesa de Neurociências (sponsored by Pfizer laboratories).

\section{References}

Anderson, S., Bankier, A.T., Barrell, B.G., de Bruijn, M.H.L., Coulson, A.R., Drouin, J., Eperon, I.C., Nierlich, D.P., Roe, B.A., Sanger, F., Schreier, P.H., Smith, A.J.H., Staden, R., Young, I.G., 1981. Sequence and organization of the human mitochondrial genome. Nature 290, $457-465$.

Andreasen, N., Blennow, K., Sjodin, C., Winblad, B., Svardsudd, K., 1999. Prevalence and incidence of clinically diagnosed memory impairments in a geographically defined general population in Sweden. The Pitea dementia project. Neuroepidemiology 18, 144-155. 
Arbustini, E., Diegoli, M., Fasani, R., Grasso, M., Morbini, P., Banchieri, N., Bellini, O., Dal Bello, B., Pilotto, A., Magrini, G., Campana, C., Fortina, P., Gavazzi, A., Narula, J., Viganò, M., 1998. Mitochondrial DNA mutations and mitochondrial abnormalities in dilated cardiomyopathy. Am. J. Pathol. 153, 1501-1510.

Barber, R., Snowden, J.S., Craufurd, D., 1995. Frontotemporal dementia and Alzheimer's disease: retrospective differentiation using information from informants. J. Neurol. Neurosurg. Psychiatry 59, 61-70.

Brun, A., 1993. Frontal lobe degeneration of non-Alzheimer type revisited. Dementia 4, 126-131.

Brun, A., Englund, B., Gustafson, L., Passant, U., Mann, D.M.A., Neary, D., Snowden, J.S., 1994. Clinical and neuropathological criteria for frontotemporal dementia: the Lund and Manchester Groups. J. Neurol. Neurosurg. Psychiatry 57, 416-418.

Buée, L., Delacourte, A., 2001. Neuronal subpopulations and genetic background in tauopathies: a catch 22 story? Neurobiol. Aging 22, $115-118$.

Chang, L., Cornford, M., Miller, B.L., Itabashi, H., Mena, I., 1995. Neuronal ultrastructural abnormalities in a patient with frontotemporal dementia and motor neuron disease. Dementia 6, 1-8.

Crook, R., Hardy, J., Duff, K., 1994. Single-day apolipoprotein E genotyping. J. Neurosci. Methods 53, 125-127.

Dickson, D.W., 1997. Neurodegenerative diseases with cytoskeletal pathology: a biochemical classification (editorial). Ann. Neurol. 42, $541-544$.

Folstein, M., Folstein, S., McHugh, P., 1975. Mini-mental state. A practical method for grading the cognitive state of patients for the clinician. J. Psychiatr. Res. 12, 189-198.

Foster, N.L., Wilhelmsen, K., Sima, A.A., Jones, M.Z., D’Amato, C.J., Gilman, S., 1997. Frontotemporal dementia and parkinsonism linked to chromosome 17: a consensus conference. Conference participants. Ann. Neurol. 41, 706-715.

Fukuda, M., Nakano, S., Imaizumi, N., Kitazawa, M., Nishizawa, M., Kigoshi, T., Uchida, K., 1999. Mitochondrial DNA mutations are associated with both decreased insulin secretion and advanced microvascular complications in Japanese diabetic subjects. J. Diabetes Its Complicat. 13, 277-283.

Goedert, M., Crowther, R.A., Garner, C.C., 1991. Molecular characterization of microtubule-associated proteins tau and MAP2. Trends Neurosci. 14, 193-199.

Gydesen, S., Brown, J.M., Brun, A., Chakrabarti, L., Gade, A., Johannsen, P., Rossor, M., Thusgaard, T., Grove, A., Yancopoulou, D., Spillantini, M.G., Fisher, E.M., Collinge, J., Sorensen, S.A., 2002. Chromosome 3 linked frontotemporal dementia (FTD-3). Neurology 59, $1585-1594$.

Herrnstadt, C., Elson, J.L., Fahy, E., Preston, G., Turnbull, D.M., Anderson, C., Ghosh, S.S., Olefsky, J.M., Beal, M.F., Davis, R.E., Howell, N., 2002. Reduced-median-network analysis of complete mitochondrial DNA coding-region sequences for the major African, Asian, and European haplogroups. Am. J. Hum. Genet. 70, 1152-1171.

Horai, S., Hayasaka, K., Kondo, R., Tsugane, K., Takahata, N., 1995. Recent African origin of modern humans revealed by complete sequences of hominoid mitochondrial DNAs. Proc. Natl. Acad. Sci. U.S.A. 92, $532-536$.

Hutton, M., Lendon, C., Rizzu, P., Baker, M., Froelich, S., Houlden, H., Pickering-Brown, S., Chakraverty, S., Isaacs, A., Grover, A., Hackett, J., Adamson, J., Lincoln, S., Dickson, D., Davies, P., Petersen, R.C., Stevens, M., de Graaff, E., Wauters, E., van Baren, J., Hillebran, M., Joosse, M., Kwon, J.M., Nowotny, P., Che, L.K., Norton, J., Morris, J.C., Reed, L.A., Trojanowski, J., Basun, H., Lannfelt, L., Neystat, M., Fahn, S., Dark, F., Tannenberg, T., Dodd, P.R., Hayward, N., Kwok, J.B.J., Schofield, P.R., Andreadis, A., Snowden, J., Craufurd, D., Neary, D., Owen, F., Oostra, B.A., Hardy, J., Goate, A., van Swieten, J., Mann, D., Lynch, T., Heutink, P., 1998. Association of missense and 5-primesplice-site mutations in tau with the inherited dementia FTDP-17. Nature 393, 702-705.

Ji, L., Hou, X., Han, X., 2001. Prevalence and clinical characteristics of mitochondrial tRNA leu(UUR) mt $3243 \mathrm{~A} \rightarrow \mathrm{G}$ and ND-1 gene mt 3316 $\mathrm{G} \rightarrow \mathrm{A}$ mutations in Chinese patients with type 2 diabetes. Chin. Med. J. (Engl.) 114, 1205-1207.

Lee, V.M.-Y., Goedert, M., Trojanowski, J.Q., 2001. Neurodegenerative tauopathies. Annu. Rev. Neurosci. 24, 1121-1159.

Lynch, T., Sano, M., Marder, K.S., Bell, K.L., Foster, N.L., Defendini, R.F., Sima, A.A.F., Keohane, C., Nygaard, T.G., Fahn, S., Mayeux, R., Rowland, L.P., Wilhelmsen, K.C., 1994. Clinical characteristics of a family with chromosome 17-linked disinhibition-dementia-parkinsonismamyotrophy complex. Neurology 44, 1878-1884.

Macaulay, V., Richards, M., Hickey, E., Vega, E., Cruciani, F., Guida, V., Scozzari, R., Bonné-Tamir, B., Sykes, B., Torroni, A., 1999. The emerging tree of west Eurasian mtDNAs: a synthesis of control-region sequences and RFLPs. Am. J. Hum. Genet. 64, 232-249.

Matsumoto, M., Hayasaka, S., Kadoi, C., Hotta, Y., Fujiki, K., Fujimaki, T., Takeda, M., Ishida, N., Endo, S., Kanai, A., 1999. Secondary mutations of mitochondrial DNA in Japanese patients with Leber's hereditary optic neuropathy. Ophthalmic Genet. 20, 153-160.

Matsuura, N., Suzuki, S., Yokota, Y., Kazahari, K., Kazahari, M., Toyota, T., Hirai, M., Okuno, A., Harada, S., Fukushima, N., Koike, A., Ito, Y., Hotsubo, T., 1999. The prevalence of mitochondrial gene mutations in childhood diabetes in Japan. J. Pediatr. Endocrinol. Metab. 12, $27-30$.

McKhann, G.M., Albert, M.S., Grossman, M., Miller, B., Dickson, D., Trojanowski, J.W., 2001. Clinical and pathological diagnosis of frontotemporal dementia: report of the work group on frontotemporal dementia and Pick's disease. Arch. Neurol. 58, 1803-1809.

Nakagawa, Y., Ikegami, H., Yamato, E., Takekawa, K., Fujisawa, T., Hamada, Y., Ueda, H., Uchigata, Y., Miki, T., Kumahara, Y., Ogihara, T., 1995. A new mitochondrial DNA mutation associated with non-insulindependent diabetes mellitus. Biochem. Biophys. Res. Commun. 2, $664-668$.

Nakano, S., Fukuda, M., Hotta, F., Ito, T., Ishii, T., Kitazawa, M., Nishizawa, M., Kigoshi, T., Kakinuma, H., Takahashi, H., Uchida, K., 1998. Mitochondrial DNA point mutation at nucleotide pair 3316 in a Japanese family with heterogeneous phenotypes of diabetes. Endocr. J. 45, $625-630$.

Neary, D., 1990. Dementia of frontal lobe type. J. Am. Geriatr. Soc. 38, $71-72$.

Odawara, M., Sasaki, K., Yamashita, K., 1996. A G-to-A substitution at nucleotide position 3316 in mitochondrial DNA is associated with Japanese non-insulin-dependent diabetes mellitus. Biochem. Biophys. Res. Commun. 227, 147-151.

Parfait, B., Rustin, P., Munnich, A., Rötig, A., 1998. Coamplification of nuclear pseudogenes and assessment of heteroplasmy of mitochondrial DNA mutations. Biochem. Biophys. Res. Commun. 217, 57-59.

Raux, G., Gantier, R., Thomas-Anterion, C., Boulliat, J., Verpillat, P., Hannequin, D., Brice, A., Frebourg, T., Campion, D., 2000. Dementia with prominent frontotemporal features associated with L113P presenilin 1 mutation. Neurology 55, 1577-1578.

Rizzu, P., Van Swieten, J.C., Joosse, M., Hasegawa, M., Stevens, M., Tibben, A., Niermeijer, M.F., Hillebrand, M., Ravid, R., Oostra, B.A., Goedert, M., van Duijn, C.M., Heutink, P., 1999. High prevalence of mutations in the microtubule-associated protein tau in a population study of frontotemporal dementia in the Netherlands. Am. J. Hum. Genet. 64, 414-421.

Rustin, P., Chretien, D., Bourgeron, T., Gérard, B., Rötig, A., Saudubray, J.M., Münnich, A., 1994. Biochemical, molecular investigations in respiratory chain deficiencies. Clin. Chim. Acta 220, 35-51.

Savioz, A., Riederer, B.M., Heutink, P., Rizzu, P., Tolnay, M., Kovari, E., Probst, A., Rieder, I.M., Bouras, C., Leuba, G., 2003. Tau and neurofilaments in a family with frontotemporal dementia unlinked to chromosome 17q21-22. Neurobiol. Dis. 12, 46-55.

Sjögren, M., Edman, A., Wallin, A., 1997. Symptomatological characteristics distinguish between frontotemporal dementia and vascular dementia with a dominating frontal lobe syndrome. Int. J. Geriatr. Psychiatry $12,656-661$. 
Sjögren, M., Rosengren, L., Minthon, L., Davidsson, P., Blennow, K., Wallin, A., 2000. Cytoskeleton proteins in CSF distinguish frontotemporal dementia from AD. Neurology 54, 1960-1964.

Spillantini, M.G., Bird, T.D., Ghetti, B., 1998. Frontotemporal dementia and Parkinsonism linked to chromosome 17: a new group of tauopathies. Brain Pathol. 8, 387-402.

Sternberg, D., Danan, C., Lombès, A., Laforêt, P., Girodon, E., Goossens, M., Amselem, S., 1998. Exhaustive scanning approach to screen all the mitochondrial tRNA genes for mutations and its application to the investigation of 35 independent patients with mitochondrial disorders. Hum. Mol. Genet. 7, 33-42.

Stevens, M., van Duijn, C.M., Kamphorst, W., de Knijff, P., Heutink, P., van Gool, W.A., Scheltens, P., Ravid, R., Oostra, B.A., Niermeijer, M.F., van Swieten, J.C., 1998. Familial aggregation in frontotemporal dementia. Neurology 50, 1541-1545.

Vermersch, P., Bordet, R., Ledoze, F., Ruchoux, M.M., Chapon, F., Thomas, P., Destee, A., Lechevallier, B., Delacourte, A., 1995. Demonstration of a specific profile of pathological tau proteins in frontotemporal dementia cases. CR Acad. Sci. 318, 439-445.

Wilhelmsen, K.C., Lynch, T., Pavlou, E., Higgins, M., Hygaard, T.G., 1994. Localization of disinhibition-dementia-parkinsonism-amyotrophy complex to $17 q 21-22$. Am. J. Hum. Genet. 55, 1159-1165.

Wilhelmsen, K.C., Miller, B., Geschwind, D., 2001. Commentary. Neurobiol. Aging 22, 119-121. 